\title{
AN INTRODUCTION OF SURVEYING AND GEOMATICS EDUCATION WITH E-PLATFORM IN NCTU, TAIWAN
}

\author{
Tee-Ann Teo ${ }^{\mathrm{a}}$, Peter Tian-Yuan Shih ${ }^{\mathrm{b}, *}$ \\ a Dept. of Civil Engineering, National Chiao Tung University, Hsinchu, Taiwan 30010 - tateo@mail.nctu.edu.tw \\ b Dept. of Civil Engineering, National Chiao Tung University, Hsinchu, Taiwan 30010 - tyshih@mail.nctu.edu.tw
}

\section{Commission VI}

KEY WORDS: Surveying, National Chiao Tung University, E-Learning Platform

\section{ABSTRACT:}

This article presents the current status of Surveying and Geomatics education provided by Department of Civil Engineering at National Chiao Tung University, Taiwan. The Surveying and Geomatics Education at NCTU is introduced first. Then the current status of using E-learning platform for Surveying and Geomatics courses is described. This platform, also known as E-Campus, is designed and implemented by NCTU Digital Content Production Center. This paper also shows some statistical numbers of Surveying and Geomatics courses using E-Campus. The practical results indicated that the average login for undergraduate student is from 38 to 60 times per student for each course while the average login for graduate student is from 69 to 105.

\section{INTRODUCTION}

National Chiao Tung University (NCTU) has a remarkably long history. This University was founded in the suburbs of Shanghai in 1896, sixteen years before the birth of the Republic of China, at the suggestion of Hsuan-Wai Shen, Minister of Foreign Affairs of the Ching Dynasty. The University was first named Nanyang College. It was established to meet the urgent need to introduce western civilization into China. Due to the insistence of Chiao Tung University alumni at home and abroad and in view of the importance of developing the electronic industry for the national economy and defence, the establishment of the National Chiao Tung University Institute of Electronics was formally recognized by the government in July 1958 in Hsinchu, Taiwan (NCTU, 2011). Though years, NCTU in Taiwan is a University with full capacity. The Department of Transport Engineering was founded in 1978 upon governmental approval, and renamed to Department of Civil Engineering in 1979 (NCTU, 2011a).

Currently, the Department of Civil Engineering has six divisions that include Construction and Management, Hydraulic and Ocean, Geotechnical, Structural, Surveying and Geomatics engineering. The Surveying division was established in 1990 and was renamed as Surveying and Geomatics division in 2001. This division offers comprehensive curricula on surveying as well as geomatics. In addition to basic Surveying, Mapping and Geodesy, considerable efforts are expended to a variety of modern research problems in 3S technologies. The courses provided by Surveying and Geomatics division are related to Geodesy, Geographic Information System (GIS), Global Positioning System (GPS), Land Surveying, Remote Sensing (RS) and etc. Most of the current courses utilize E-learning platform in teaching.

There are two E-Learning platforms at NCTU, i.e. Moodle (http://moodle.nctu.edu.tw) (Moodle, 2011) and E-campus (http://dcpc.nctu.edu.tw) (NCTU, 2011b). NCTU has adopted Moodle system since 2010 as it is a free web application for Elearning. E-campus is designed and implemented by NCTU
Digital Content Production Center in 2003. This E-campus is equipped with complete functions in teaching and learning. Besides, E-campus is able to connect, import and export databases from other educational systems in NCTU, for example, Student Registration System and Course Election System. Hence, most of the courses in NCTU use E-campus as a supporting platform.

The structure of this paper includes two parts. The first part is to introduce Surveying and Geomatics Education in NCTU. The second part is to introduce Surveying and Geomatics courses using E-learning system.

\section{SURVEYING AND GEOMATICS EDUCATION IN NCTU}

In the undergraduate level, students are not specialized in a particular division. The Surveying and Geomatics division is responsible for both mandatory and elective courses in the field. In the graduate level, students are enrolled into a selected division and the courses are specialized.

\subsection{Introduction to Surveying and Geomatics Division}

The surveying division of Department of Civil Engineering at NCTU currently has three full-time and three adjunct faculty members. It usually recruits two $\mathrm{PhD}$ students and eight master students per school year depending on the number of applicants. This division maintains and operates Surveying Laboratory, for supporting instruments required for related courses, particularly surveying exercises. The research activities are focused on Geodesy, GIS, GPS, gravity, lidar, photogrammetry, remote sensing, cyber city and others. The facilities include different types of surveying equipment such as Automatic Levels, Digital Levels, Theodolites, Total Stations, GNSS/GPS Systems, gravimeter, and related software, such as BAE Socet GXP, ERDAS Imagine, MicroSurvey, Bernese GPS processing package, and many others.

\footnotetext{
* Corresponding author.
} 


\subsection{Course related to Surveying and Geomatics Division}

Currently, undergraduate courses related to Surveying and Geomatics include "Surveying (I) \& (II)", "Engineering Graphic (I) \& (II)”, "Photogrammetry and Remote Sensing”, "Statistic Adjustment", "Introduction to Global Positioning System", and others. The courses are designed to satisfy the needs of Civil Engineering as well as other engineering divisions.

The graduate program of Surveying and Geomatics Engineering encompasses in both instruction and research activities. Graduate courses include "Physical Geodesy", "Satellite Geodesy”, "Adjustment and Statistics", "Global Positioning System”, “Geographic Information System”, “Advanced Topics on Terrain Mapping", "Remote Sensing", "Digital Photogrammetry”, "Deformation Surveying and Analysis”, and others.

\section{E-LEARNING PLATFORM AT NCTU}

The available E-Learning platforms at NCTU are Moodle and E-campus. Moodle is an open source. Its detailed information can be found at http://moodle.org. Only the E-campus system is described in this paper as all the current courses in Surveying and Geomatics division are using this platform.

The main purpose of E-campus system is to support the teaching and learning using internet. It is able to connect other educational systems such as Student Registration System and Course Election System in NCTU. The latest version is E3 (http://e3.nctu.edu.tw). Figure 1 is the main page of E-campus after login. The basic information of user can be modified in this page. User may select current or previous courses in this main page. The defaulted courses are shown on the left hand side according to the semester. This main page contains all the basic information of the courses and announcements from the system administrators.

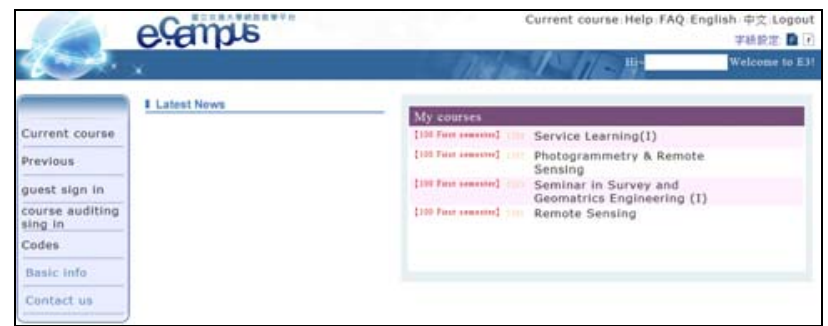

Figure 1. Main page of E-Campus.

Once the user has selected a course, it will switch to the webpage of the selected course. There are four control panels to obtain the course information, i.e., Class-info, Materials, Scores and Tools. Figure 2 is the control panels of each course.

"Class-info" comprises syllabus, members and announcements of the course. The members section lists all the contact information of the teachers, teaching assistants and enrolled students. Only the lecturer and authorized teaching assistants are able to post news on this webpage. The system makes a record and sends a message via email to all students automatically after the announcement was posted.

\begin{tabular}{|c|c|}
\hline Classinfo & Materials \\
\hline $\begin{array}{l}\text { course home } \\
\text { page }\end{array}$ & Documents \\
\hline Introduction & Assignments \\
\hline members & Discussion \\
\hline announcements & $\begin{array}{l}\text { Discussions - } \\
\text { Model }\end{array}$ \\
\hline Scores & Tools \\
\hline Active study & Mail \\
\hline record & Import all \\
\hline Scores & course \\
\hline & Site Map \\
\hline Percentage & Theme Setting \\
\hline $\begin{array}{l}\text { All grade } \\
\text { setting }\end{array}$ & $\begin{array}{l}\text { Value-added } \\
\text { features }\end{array}$ \\
\hline
\end{tabular}

Figure 2. Control panels of each course.

"Materials" is the most important part. It contains of the digital file of documents, assignments, and forum. Students may download the latest course materials in this section. They can also download and upload their assignments via this system. The lecturer is able to view their homework and grade them at the system as well. Hence, the hardcopy of homework is not a must. Forum is a good way to ask and discuss questions after class. Usually, the questions are provided by the lecturer.

"Scores" is not only to give the scores for assignments and exams, more important, it record the login information for each student. It is good to know the students' activities via this platform. For example, who login often and who does not? The lecturer can set up the layout of the grades in different ways, for example, to announce individually to each student or to show all the grades.

The last part includes some useful tools, such as email system, import course information from previous semester, site maps, themes of webpage, and other advance settings. The lecturer can send email to any members via this system; so, the lecturer does not need to find the email address for each member. Figure 3 is an overview of the webpage. All the available functions are listed on this site map.

More than 50\% of courses in NCTU, including Surveying and Geomatics division, use E-campus as a supporting E-learning platform. The major advantages are: (1) It is a one-stop services that the user is able to obtain all the related information in one web-page. (2) It is easy to share the learning materials, supplemental documents and also assignments. (3) The forum is a place of interaction after class. The students may ask and answer the question via the platform without the time constraint. (4) The log file records all the students' activities which could be further used for analysis. 


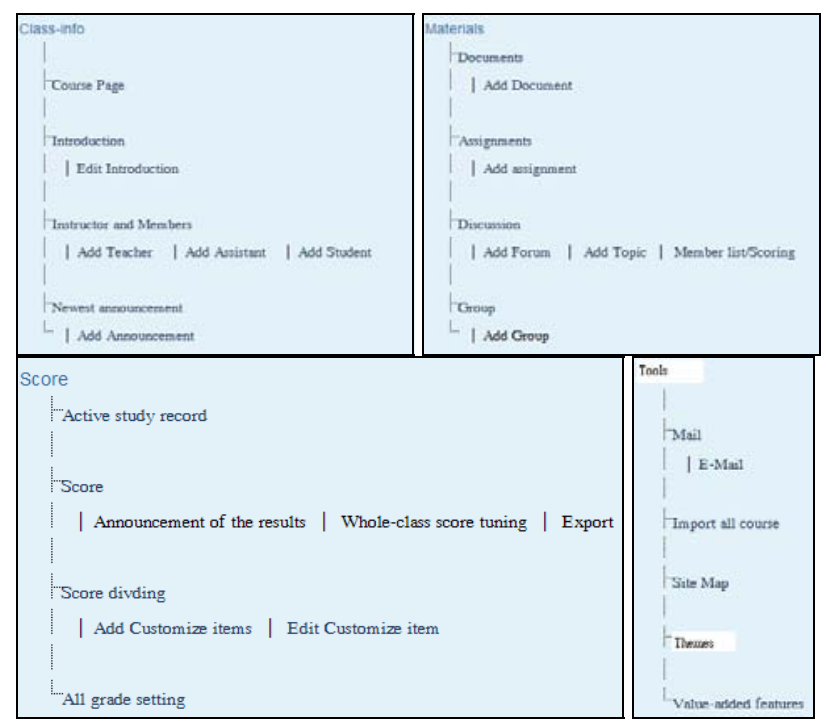

Figure 3. Site map of course.

The following section provides some statistical numbers of Surveying and Geomatics courses using E-Campus. The practical cases include the courses in undergraduate and graduate programs. They are "Surveying (I)", "Engineering Graphic (I) \& (II)”, "GIS”, "RS” and "Digital Photogrammetry". Table 1 summaries the result of the three compulsory courses in the undergraduate program using E-Campus platform. The number of student indicates the total number of enrolled student. The compulsory courses always have more than 50 students per class. All the learning materials are uploaded to E-campus and the number of material are stated as Table 1. E-campus also records all the login information from each student. The average numbers of login within a semester are ranged from 38 to 60 times per student. The duration of semester is about 126 days. Hence, the student had logged-in to E-campus not longer than 3 days.

Table 2 is the result of the three courses in the graduate program. The average numbers of login are ranged from 69 to 105 times per student. Graduate students have higher logged-in frequency to this E-campus than the undergraduate students. In average, every student had logged-in to the system not longer than 1.8 days.

Table 1. Results of the three compulsory courses in the undergraduate program.

\begin{tabular}{|c|c|c|c|}
\hline \multirow{2}{*}{ Item } & \multirow{2}{*}{$\begin{array}{l}\text { Surveying } \\
\text { (I) }\end{array}$} & \multicolumn{2}{|c|}{ Engineering Graphic } \\
\hline & & (I) & (II) \\
\hline Number of student & 60 & 116 & 106 \\
\hline Number of materials & 21 & 18 & 14 \\
\hline Number of assignment & $0^{\#}$ & 9 & 6 \\
\hline Number of login & 2277 & 6686 & 6352 \\
\hline Average login per student & 38 & 58 & 60 \\
\hline
\end{tabular}

${ }^{\#}$ No assignment, but 9 quizzes

Table 2. Results of the three courses in the graduate program.

\begin{tabular}{|l|r|r|r|}
\hline Item & GIS & \multicolumn{1}{|c|}{ RS } & $\begin{array}{c}\text { Digital } \\
\text { Photogrammetry }\end{array}$ \\
\hline Number of student & 10 & 10 & 6 \\
\hline Number of materials & 19 & 11 & 12 \\
\hline Number of assignment & 5 & 6 & 9 \\
\hline Number of login & 1052 & 808 & 412 \\
\hline Average login per student & 105 & 81 & 69 \\
\hline
\end{tabular}

\section{CONCLUSIONS}

In this paper, the Surveying and Geomatics Education at National Chiao Tung University in Taiwan is briefly introduced. This paper also reported the E-learning platform constructed by Digital Content Production Center at NCTU. This platform is designed to fulfill the needs of teaching and learning. Four modules included by this platform are Class-info, Materials, Scores, and Tools. This paper also showed some statistical numbers of Surveying and Geomatics courses using E-Campus. The practical results indicated that the average login for undergraduate students is from 38 to 60 times per student while the average login for graduate students is from 69 to 105 times per student.

\section{REFERENCES}

Moodle, 2011. Open-source community-based tools for learning, http://www.model.org (accessed 1 Sep. 2011) NCTU, 2011. History of NCTU, http://www.nctu.edu.tw/english/history.htm (accessed Sept. 11, 2011)

NCTU, 2011a. Department of Civil Engineering, http://www.cv.nctu.edu.tw (accessed 1 Sep. 2011)

NCTU, 2011b. eCampus: Digital Content Product Center, http://www.dcpc.nctu.edu.tw (accessed 1 Sep. 2011) 